\title{
Post COVID-19 Impacts on Technology Adoption
}

\author{
Ibrahim Atoum, Nasser Al Jarallah
}

\begin{abstract}
This research paper analyzes the current technology adoption in the context of the COVID-19 pandemic. This worldwide health emergency condition has led to people being confined, and due to this confinement, the closure of education centers and face-to-face education led to online education. Teachers are forced to adapt to their custody, new methodological approaches, and dizzying pace, which present excellent stress levels. In the field of managing motivational and emotional processes, neuroeducation contribution leads to students' meaningful learning. The symbiosis of neuroeducation and Communication Technology (ICT) creates a significant contribution in shifting of paradigm active today. Technology Company's contribution to the COVID-19 pandemic is dependent on a relatively digital ecosystem while attracting various investors despite capital outflows. Moreover, this contribution is connected to the technology company's capability to quickly pivot towards new models and services and deliver goods and services to the underserved in many cost-effective ways.
\end{abstract}

Keywords: COVID-19, ICT, Digital Epidemiological, neuroeducation, digital payments.

\section{INTRODUCTION} countries, middle-income countries, and high-income in the availability of technology and digital usage solutions due to the COVID-19 pandemic to support its response. The use of technology by teenagers worldwide has rapidly changed because of the impact of the COVID-19 pandemic on dayto-day activities. Under the COVID-19 pandemic threat, the current context has led to transformations in various spheres of labor, political, economic, and social life. The technological revolution has transformed various aspects of life [1]. The technology system-level approach is required to inform how digital strategies are incorporated into the control of COVID-19 control and to prepare for future pandemics. The International Health Regulations require all countries to have a central capacity to ensure preparedness for infectious diseases, which can spread internationally [2]. New technologies and research and development methods to strengthen the central capacities when innovation is a critical necessity often occur during pandemic outbreaks. During these quarantines and lockdowns, technology has played a significant role in maintaining our society's function.

Manuscript received on September 03, 2021.

Revised Manuscript received on September 07, 2021.

Manuscript published on September 30, 2021.

* Correspondence Author

Ibrahim*, Department of Computer Science and Information Systems, Applied Sciences College, AlMaarefa University, Riyadh, Saudi Arabia. Email: iotoum@mcst.edu.sa.

Nasser, Vice Rector, AlMaarefa University, Riyadh, Saudi Arabia. Email: njarallah@mcst.edu.sa.

(C) The Authors. Published by Blue Eyes Intelligence Engineering and Sciences Publication (BEIESP). This is an open access article under the CC BY-NC-ND license (http://creativecommons.org/licenses/by-nc-nd/4.0/)
There has been a considerable exposure between poorer

There has been an outbreak measure response by the publichealth support relevant today, including community transmission interruption, rapid case identification, solid public communication, and surveillance [3]. It is essential to monitor how the outbreak measures are implemented and their effect on mortality and incidence.

The purpose of this research paper is to outline a proposal that optimizes the work of all institutions such as health, manufacturing, and education professions in the context of the pandemic by Information and Communication Technologies (ICT), and reviews how the technology are harnessed to COVID-19 response by the public-health worldwide.

\section{SURVEILLANCE OF DIGITAL EPIDEMIOLOGICAL}

The understanding pandemic outbreak in person, time and place, and disease identification of the risk factors guiding practical innovation are the core function of public health. Public health uses a wide range of digital information sources to interpret and enhance epidemiological data [4]. Notification of diagnosed cases by the clinicians, laboratory health-related data, and syndromic networks surveillance is relied on to establish population surveillance and early detection of diseases through online information sources.

\section{IDENTIFICATION OF THE RAPID CASE}

Rapid and early case identification is significant after the outbreak of the COVID-19 pandemic for the appropriate contacts and isolation of cases to decrease the ongoing spread and understanding modes and critical risks of transmission. With an estimate that $85 \%$ of COVID-19 cases are asymptomatic and mild, contact tracing and widespread testing of the population have a significant role in case identification [3]. Various wearable technology is being innovated for monitoring the pandemic in population. Machine algorithms are introduced for case identification by digital differentiation of the COVID-19 through hospital chest scan use by computer tomography from communityacquired pneumonia.

\section{DISCONTINUOUS COMMUNITY TRANSMISSION AFTER COVID-19 PANDEMIC}

Quarantine and rapid tracing prevent further transmission after case isolation and identification [2]. In cases of high information, the monitoring and implementation of the technology, interventions are required at a large scale, which is becoming at least rigorous by the traditional means. Without digital instruments, tracing of digital contact automates drafting on speed and scale is difficult to replace. Particularly in high-populated locations, with a population that is mobile digital contact tracing aids to minimize human recall reliance [1].

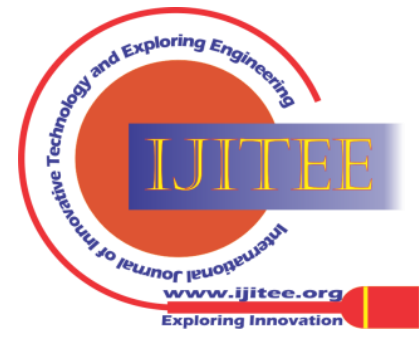


There has been a rapid development of digital tracing apps in various countries in the COVID-19 pandemic; these apps depend on technologies and approaches. It is essential in evaluating their effectiveness and accuracy [4]. Adoption is limited by handset and usability compatibility, user trust, and smartphone ownership.

\section{PUBLIC COMMUNICATION IN INFORMING POPULATIONS}

After the COVID-19 pandemic, effective interventions depend on public cooperation and education, supported by effective communications strategies such as active society participation to enable public trust. In general, communication, social media, and online data are vibrant and play an essential role. The United Nations spread COVID-19 pandemic information on national websites, and to the population who have limited access to the internet, text messages are used [3]. Technology companies and public-health organizations create efforts to reduce the widespread of misinformation and to implement trusted news sites such as Google intervention and WHO prioritization.

Digital communication programs are supporting Socialdistance measures. Through video conferencing, people can quickly attend classes and work from their homes, while mental health is widely supported by online services [2]. In ways to help and support those in need, digital platforms enable efforts of community mobilization. In addition, privacy and the security communication platforms, especially the healthcare confidential information flow, remain a concern.

\section{ENABLING NUMEROUS RESPONSES TO THE COVID-19 PANDEMIC THROUGH DISRUPTIVE TECHNOLOGIES}

There has been an increase in technology use after the COVID-19 pandemic compared to the year 2019 first quarter, where mobile businesses, citizens, and governments experience usage where mobile and internet usage grew more rapidly in the year 2020 first quarter, as a dramatic change [4]. Despite these challenges, businesses, individuals, and governments use disruptive technology in responding to COVID-19 pandemic crises worldwide.

\section{HEALTH CRISIS RESPOND}

Various hospitals in high and middle-income countries can provide quick online healthcare services and waive telemedicine restrictions. Through technology, the nation's blockchain and epidemic Surveilling platforms have been launched to help track COVID-19 progress in all provinces in registering significant epidemic information and in realtime on the chain to ensure that the data is not tampered with and can be easily traced [3]. Robots are now disinfecting hospitals and delivering medications, foods and screening patients' temperatures, aiding reduce exposure of healthcare workers to the pandemic.

\section{CREATING EFFORTS OF BUILDING RESILIENCE}

Using numerous media such as television, internet, text messages, and radio, education institutions worldwide have significantly shifted to online instructions [4].
Manufacturing institutions and companies rely on new technology such as 3D printing and robotics to manage social distancing. The poorest acquire social welfare programs by introducing disruptive technology such as big information analytics and digital platforms [2]. Large companies like agribusiness leveraged telecommuting apps such as Skype, Zoom, and Microsoft Teams to aid 90\% of its employees to work from home.

\section{TECHNOLOGICAL TRENDS AFTER COVID-19 PANDEMIC}

After the COVID-19 pandemic, technology trends such as telehealth, robotics, and payments have been accelerated, and these technologies create an everlasting impact after COVID-19 [5]. Technology advancement aid enhances the effect on how individuals conduct their business, how they work, trade, learn, produce goods, entertain, and how they inquire about their medical services.

\section{ROBOT DELIVERIES AND ONLINE SHOPPING}

This pandemic has dramatically transformed online shopping from better to best worldwide. Various bars and restaurants in Beijing have created offers such as happy hours through online delivery and orders [6]. Robust logistics systems need to support online shopping while different delivery restaurants and companies in China and the United States of America launch delivery services where products are dropped or picked up at designated areas [7]. Deliveries by robots are developed by Chinese e-commerce. Delivery companies are required to create clear protocols to safeguard delivered goods' sanitary conditions.

\section{CONTACTLESS AND DIGITAL PAYMENTS}

Central banks have implemented various measures in South Korea, the United States of America, and China to ensure that banknotes are clean from the virus before circulating [8]. After COVID-19, contactless online payments in e-wallets and cards are recommended to prevent COVID-19 processes [6]. It enables the population to inquire about online price and purchase utility, goods, and services payments. Digital payment availability relies on internet devices, networks, and availability to convert cash to digitalized format.

\section{REMOTE WORK AND DISTANCE LEARNING}

Technology enables remote work such as voice over internet protocol (VoIP), cloud technology, financial recognition, a virtual private network (VPNs), work collaboration tools, and virtual meetings technologies aid individuals to appear before the virtual background to prevent home privacy [7]. Moreover, viruses spread prevention through remote work provides flexibility and saves time. Remote work creates challenges for employees and employers and imposes complicated labor law issues like income tax and a safe work environment [6].

Published By:

Blue Eyes Intelligence Engineering and Sciences Publication

(C) Copyright: All rights reserved.

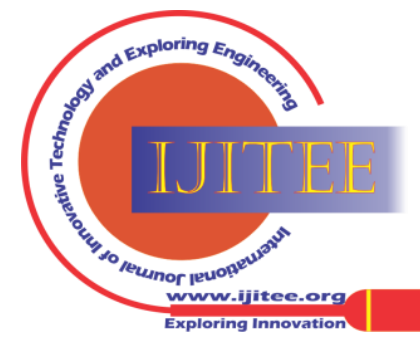


After the COVID-19 pandemic, employers implement remote work by hiring individuals with low labor costs [8]. Understanding slight work effects on the population psychological, regulations and laws need to be updated to enable remote work accommodation. After the COVID-19 outbreak, quarantine measures led to education institutions offering online causes to ensure no education disruption [9]. Distance learning technologies include 3D printing, virtual reality, remote intelligent teachers, and augmented reality [10]. Distance learning concerns include technology possibilities that create a significant divide in income levels and digital readiness.

\section{TELEHEALTH, ONLINE ENTERTAINMENT, AND SUPPLY CHAIN}

Telehealth creates a playful way of containing COVID-19 spread and providing critical primary care. Chatbots and wearable personal loT tools make initial diagnoses found on signs and symptoms identified patients [9]. Telehealth requires excellent internet connection and high levels of literacy technology.

Despite quarantine measures decreasing personal interactions, human intelligence has aided people more together online [10]. Chinese films companies and international and museums heritage sites release films and offer virtual tours, respectively. COVID-19 has disrupted the global supply outbreak, while some companies are wholly closed with quarantine and distancing orders [11]. Inadequate data visibility, inadequate flexibility, and diversity have made the current supply chain vulnerable to any outbreak pandemic [12]. Core technology such as cloud computing, blockchain, and Big Data build more supply chain resilient management by encouraging information sharing and enhancing data accuracy.

\section{PRINTING, DRONES, AND ROBOTICS}

3D printing technology has been advanced and implemented to mitigate export bans and supply chain shocks on personal protective equipment [8]. Flexibility in product production is offered by $3 \mathrm{D}$ printing and can produce various products based on different design materials and files. Human interactions have highly relied on labor interactions such as logistics, food, retail, and manufacturing, which are the most affected after the COVID-19 pandemic [10]. Those in quarantine can now receive food by the use of robots and drones.

\section{INFORMATION AND COMMUNICATIONS TECHNOLOGY (ICT) AND 5G}

Technology today relies on high-speed, affordable, and stable internet. 5G adoption has shown significance in healthcare consultation and remote monitoring, increasing data plan cost and device compatibility.

\section{CONCLUSION}

With the ongoing COVID-19 pandemic, it is challenging to quantify digital technology's benefit to the response of the pandemic. Digital technologies play a significant role in a comprehensive response to future pandemics and outbreaks, creating public health measures hence contributing to reducing economic and human impact on the COVID-19 pandemic. Due to the COVID-19 pandemic, data sharing, increase in innovation on local needs. research work

\section{REFERENCES} essential with the participation of the community to evolve besides digital healthcare and mobile emerging fields. The public health future is likely to rise rapidly and recognizing the significance of digital technology. Public health must put International strategies in place to align evaluation, regulation, and digital technology usage to strengthen future and pandemic preparedness for various infectious diseases and COVID-19. This research paper highlights findings brought after the COVID-19 pandemic, where emerging markets are expected to undergo an acceleration in technology adoption and online business platforms and models proliferation. The rate of acceleration is estimated to be faster in high-income countries than in

\section{ACKNOWLEDGMENT}

The authors would like to acknowledge the support provided by AlMaarefa University while conducting this

1. Kennig, I. (2019). THEORETICAL BASES OF PROFESSIONAL TRAINING OF PRACTICAL PSYCHOLOGISTS IN THE EDUCATIONAL SYSTEM OF GERMANY UNDER THE BOLOGNA PROCESS. TECHNOLOGIES of INTELLECT DEVELOPMENT, 3(1). https://doi.org/10.31108/3.2019.3.1.7.

2. Budd, J., Miller, B. S., Manning, E. M., Lampos, V., Zhuang, M., Edelstein, M., Rees, G., Emery, V. C., Stevens, M. M., Keegan, N., Short, M. J., Pillay, D., Manley, E., Cox, I. J., Heymann, D., Johnson, A. M., \& McKendry, R. A. (2020). Digital technologies in the publichealth response to COVID-19. Nature Medicine, 26(8), 1183-1192. https://doi.org/10.1038/s41591-020-1011-4

3. Alhajjaj, A. H., Aldarweesh, H. H., \& Alghawi, Z. A. (2020). Knowledge, Attitude, and Awareness Related to COVID-19 Pandemic Among the Public, Saudi Arabia: A Cross-Sectional Descriptive Study. European Journal of Medical and Educational Technologies, 13(3), em2013. https://doi.org/10.30935/ejmets/8488.

4. J. Adriaenssen, D., A. Johannessen, D., \& Johannessen, J.-A. (2016). Knowledge management and performance: developing a theoretical approach to knowledge workers' productivity, and practical tools for managers. Problems and Perspectives in Management, 14(3), 667676. https://doi.org/10.21511/ppm.14(3-3).2016.10. EDUCATIONAL TECHNOLOGIES FOR TRAINING HIGHLY https://doi.org/10.15863/tas.2019.07.75.30.

6. MAZILESCU, C.-A. (2019). Book Review EDUCATIONAL PSYCHOLOGY. THEORETICAL AND PRACTICAL LANDMARKS. Pro Edu. International Journal of Educational Sciences, 1(1), 66-69. https://doi.org/10.26520/peijes.2019.1.1.66-69.

7. McKinsey \& Company. (2020, October 5). How COVID-19 has pushed companies over the technology tipping point--and transformed business forever | McKinsey. Www.mckinsey.com. https://www.mckinsey.com/business-functions/strategy-andcorporate-finance/our-insights/how-covid-19-has-pushed-companiesover-the-technology-tipping-point-and-transformed-business-forever.

8. Shchegoleva, N., \& Lapin, N. (2021). The influence of the COVID-19 pandemic on the transformation of global value chains. Theoretical and Practical Aspects of Management, 2021(6), 6-22. https://doi.org/10.46486/0234-4505-2021-6-6-22.

9. Xiao, Y., \& Fan, Z. (2020, April 27). 10 tech trends getting us through the COVID-19 pandemic. World Economic Forum. https://www.weforum.org/agenda/2020/04/10-technology-trendscoronavirus-covid19-pandemic-robotics-telehealth/.

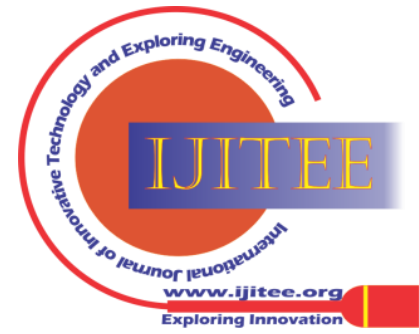




\section{Post COVID-19 Impacts on Technology Adoption}

10. Muratov, E. I. (2020). IMPROVING THE QUALITY OF THE EDUCATIONAL SYSTEM OF HIGHER EDUCATIONAL INSTITUTIONS BY MEANS OF THE INVOLVEMENT OF STUDENTS IN THE EDUCATIONAL PROCESS WITH THE USE OF ANALYTICAL POSSIBILITIES OF NEURAL NETWORK TECHNOLOGIES. Theoretical \& Applied Science, 89(09), 21-23. https://doi.org/10.15863/tas.2020.09.89.6.

11. Zalat, M. M., Hamed, M. S., \& Bolbol, S. A. (2021). The experiences, challenges, and acceptance of e-learning as a tool for teaching during the COVID-19 pandemic among university medical staff. PLOS ONE, 16(3), e0248758. https://doi.org/10.1371/journal.pone.0248758

12. Yan, S. (2021). COVID -19 and technology use by teenagers: A case study. Human Behavior and Emerging Technologies, 3(1), 185-193. https://doi.org/10.1002/hbe2.236.

\section{AUTHORS PROFILE}

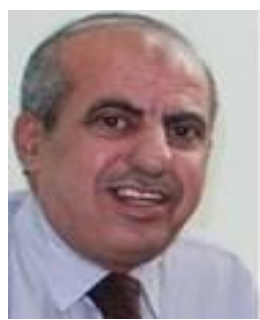

Ibrahim A. Atoum is currently working as Assistant Professor in the Department of Computer science and Information Systems at AlMaarefa University, Saudi Arabia, Riyadh. He acquired his Bachelor's degree in Computer Science from Yarmouk University, Jordan in 1985. He obtained his Master's degree in Software Development from Huddersfield University, United Kingdom in 2000 and Ph.D. degree from Bradford University, United Kingdom in 2013. He has over 20 years of experience in teaching. His areas of interests include Solar Image processing, Healthcare industry and big data, Artificial Intelligence and Mobile computing and Big data and Artificial Intelligence.

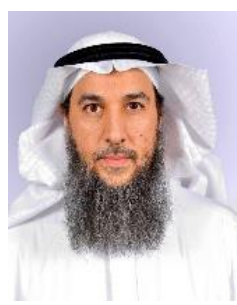

Nasser AlJaraAllah is an Assistant Professor at AlMajmaah University, who is working currently as Vice Rector of AlMaarefa University, Riyadh, Saudi Arabia. He received his bachelor degree in Health Services Administration from King Saud University, Riyadh, Saudi Arabia, his Master in Health and Hospitals Administration from King Saud University and his Business Administration Doctorate in Contemporary Management Strategies from University of Hull, UK. His research interests are big data and health care industry, information analysis in healthcare, and Excellence and Entrepreneurship.

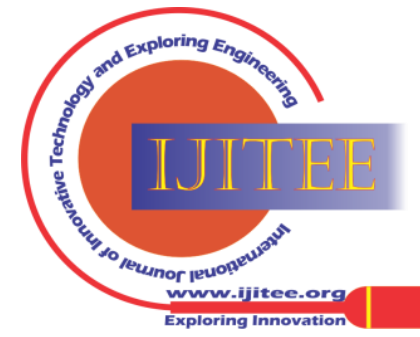

